26(1), 15-22

\title{
The Effect Measures for Diagnostic Test: A Graph Approach
}

\author{
Tae-Kyoung Cho ${ }^{a, 1}$. Chang-Kyoon $\mathrm{Son}^{a}$ \\ ${ }^{a}$ Department of Information \& Statistics Science, Dongguk University
}

(Received October 15, 2012; Revised November 12, 2012; Accepted November 27, 2012)

\begin{abstract}
In clinical study or epidemic research, the $2 \times 2$ frequency table is useful to present a summary statistic. The values of four cells in $2 \times 2$ table use to calculate the effect measures such as risk ratio, relative risk ratio or odds ratio. In this paper, we suggest that the improved visualization method using a radar diagram supported by MS-office Excel from the $2 \times 2$ frequency table is able to understand and draw easily betweendiagnostic measures such as sensitivity, specificity, predictivity, and likelihood ratio. We use some numerical example in order to show the usage of the proposed method.
\end{abstract}

Keywords: Diagnostic test, sensitivity, specificity, predictivity, likelihood ratio.

\section{1. 서론}

진단 검사(diagnostic test)의 목적은 개인의 질병 유무를 판단하는데 도움을 주기위한 것이다. 질병이 있을 수도 있고 없을 수도 있으며, 진단 검사결과는 양성일 수도 있고, 음성일 수도 있다. 따라서 질병유 무와 검사결과는 Table 1.1과 같이 네 가지 조합으로 나타낼 수 있다. 이 조합들 중에서 두 가지는 올바 른 진단결과를 제공하고, 다른 두 가지는 잘못된 진단결과를 제공하고 있다.

Kraemer (2004)는 $2 \times 2$ 빈도표는 간단하지만 결론을 유추해내기 위해서 선택하는 측도들은 연구 분야 에 따라서 부분적으로 서로 다른 관점을 가지고 있을 뿐 아니라 측도들의 일반적인 함수 형태만으로는 이들의 관계를 이해하는 것이 쉽지 않다고 지적하고 있다.

질병 유무를 결정할 수 있는 절대적으로 정확한 검사방법이 있어서, 이 방법에 의한 결과와 비교하여 다 른 검사들의 정확도가 결정될 수 있는 상황에서만 이러한 분류가 가능하다. 실제로 이와 같이 정확한 검 사방법은 이용하기 어렵고 매우 비싸기 때문에 임상 의사들은 일상적인 진료에서는 보다 간단하고 비교 적 저렴한 진단적 검사에 의존하여 환자의 처치를 결정한다. 따라서 새로운 진단적 검사 방법은 의료현 장에서 사용하기 전에 반드시 평가를 받아야한다 (Bradly, 1999).

통상적으로 새로운 진단 검사방법을 평가하는 척도로서는 일반적으로 4 가지 척도가 이용되는데, 민감 도(sensitivity), 특이도(specificity), 우도비(likelihood ratio) 그리고 예측도(predictivity) 등이다. 앞 에서 언급한 연구대상이 되는 집단에 대해서는 민감도와 특이도를 통해 보다 엄격한 평가가 수행되 고(병리검사), 그렇지 않은 집단에 대해서는 일반검사를 수행하게 된다 (Linn, 2005).

\footnotetext{
${ }^{1}$ Corresponding author: Professor, Department of Information \& Statistics Science, Dongguk University, 707 Seokjang-Dong, Gyungju, Gyeongbuk 780-714, Korea. E-mail: tkcho@dongguk.ac.kr
} 
Table 1.1. Relation of test and disease

\begin{tabular}{cccc}
\hline & & \multicolumn{2}{c}{ Disease } \\
\cline { 3 - 3 } & & Present $(\mathrm{S}+)$ & Absent $(\mathrm{S}-)$ \\
\hline Test & positive $(\mathrm{T}+)$ & true positive & false negative \\
Result & negative $(\mathrm{T}-)$ & false positive & true negative \\
\hline
\end{tabular}

Table 2.1. Result of diagnostic test

\begin{tabular}{ccccc}
\hline & & \multicolumn{2}{c}{ Disease } & Total \\
\cline { 3 - 4 } & & Present & Absent & $a+b$ \\
Clinical & Positive & $a$ & $b$ & $c+d$ \\
Test & Negative & $c$ & $d$ & $a+b+c+d$ \\
\hline
\end{tabular}

Walter (2000)은 역학 자료에 대한 주효 측도의 선택은 측도 자체의 문제보다 자료 분석의 목적에 따라 달라질 수 있다고 지적하고 있으나, 새로운 진단 검사 방법을 평가하는 측도 중에서 일반적으로 사용되 는 측도는 민감도, 특이도, 의양성 비율(false positive rate), 의음성 비율(false negative rate), 양성 우 도비(positive likelihood ratio), 음성 우도비(negative likelihood ratio)이다.

Johnson (1999)은 $2 \times 2$ 빈도표로부터 얻어진 측도들의 함수 형태만으로는 그들을 이해하는데 혼란스러 울 수 있다고 지적하고, 이러한 문제를 해결하기위해 그래프 방법을 제시하였다. 그러나 그가 제시한 그 래프 방법은 2 차원 평면상에서 사각형의 면적을 이용하여 측도들의 특성을 표현하고 있으나, 측도들 간 의 관계에 대한 정보를 나타내지 못하고 있으며, 그래프작성이 어려워 범용 프로그램을 이용하는데는 한 계가 있다.

본 논문에서는 범용 프로그램인 Microsoft Excel (Michael, 2007)로 방사형 그림을 작성하여 진단 검사 를 평가하는 여러 측도들을 그래프로 나타내고, 이들의 특성이나 관계를 이해하는데 시각적인 도움이 되 도록 제안하였다.

\section{2. 진단 검사 평가측도의 정의와 방사선 그래프}

\section{1. 진단 검사 평가측도의 정의}

진단 검사는 비용이 적게 들고, 적용하기 쉽고, 일반이 수용할 수 있고, 재현성이 높고 정밀해야 한다. 검사 결과가 일정하게 나온다면 재현성이 높은 것이고, 질병 유무를 올바르게 구분 할 수 있다면 타당도 가 높은 것이라 할 수 있다. 타당도는 민감도와 특이도로 측정된다. 민감도는 진단 검사를 받은 집단 중 에 질병이 있는 사람을 질병이 있는 사람으로 정확히 판정하는 비율이며, 특이도는 건강한 사람을 건강 한 사람으로 정확히 판정하는 비율이다. 서론에서도 언급한 바와 같이 질병유무와 검사 결과는 네 가지 조합으로 나타낼 수 있으며, 각각의 조합의 빈도가 Table 2.1과 같다고 하면 Linn (2005)에서 언급한 바 와 같이 진단 측도들을 정의하면 다음과 같다.
a) 민감도 : $\mathrm{Se}=\frac{a}{a+c}$
b) 특이도 : $\mathrm{Sp}=\frac{d}{b+d}$
c) 의양성 비율 : $\mathrm{FPR}=1-\mathrm{Sp}=\frac{b}{b+d}$
d) 의음성 비율 : $\mathrm{FNR}=1-\mathrm{Se}=\frac{c}{a+c}$ 


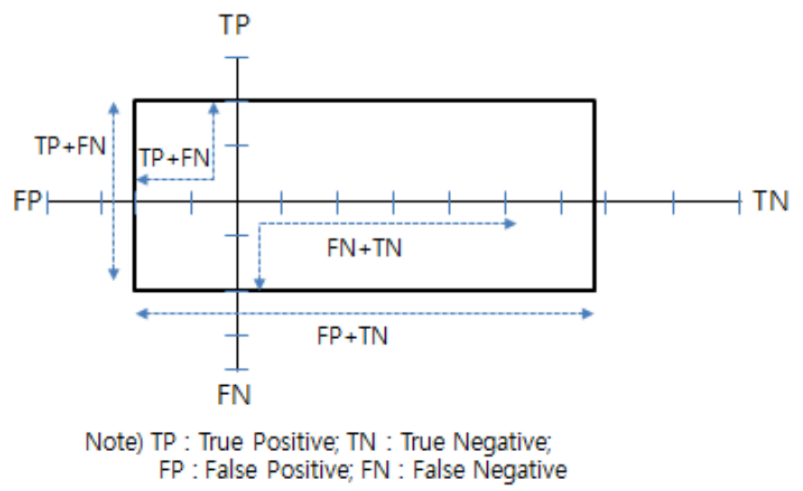

Figure 2.1. The $2 \times 2$ diagram

e) 양성우도비 : $\mathrm{PLR}=\frac{\mathrm{Se}}{1-\mathrm{Sp}}=\frac{\mathrm{Se}}{\mathrm{FPR}}=\frac{a}{a+c} / \frac{b}{b+d}=\frac{a(b+d)}{b(a+c)}$

f) 음성우도비 : $\mathrm{NLR}=\frac{1-\mathrm{Se}}{\mathrm{Sp}}=\frac{\mathrm{FNR}}{\mathrm{Sp}}=\frac{c}{a+c} / \frac{d}{b+d}=\frac{c(b+d)}{d(a+c)}$

의양성 비율은 진단 검사를 받은 사람들 중에 질병이 있는 사람을 질병이 없는 사람을 질병이 있는 사람 으로 판정하는 비율, $1-\mathrm{Sp}$ 을 나타내며, 의음성은 진단 검사를 받은 사람들 중에 질병이 있는 사람을 질병이 없는 사람으로 판정하는 비율, $1-\mathrm{Se}$ 을 나타낸다.

양성 우도비는 질병이 있는 사람을 질병이 있는 사람으로 판정하는 비율을 건강한 사람을 질병이 있 는 사람으로 판정하는 비율과 비교한 비율이다. 따라서 만약 양성 우도비(positive likelihood rate; $\mathrm{PLR}$ )의 값이 1 이면, 즉 $\mathrm{PLR}=1$, 진단검사 방법은 의미가 없다고 할 수 있다. 음성 우도비(negative likelihood rate; NLR)는 질병이 있는 사람을 건강한 사람으로 판정하는 비율을 건강한 사람을 건강한 사람으로 판정하는 비율과 비교한 비율이다. 따라서 음성 우도비의 값이 작을수록 진단검사 방법이 타 당하다고 할 수 있다 (Ransohoff, 2002).

위에서 정의한 a) f)의 진단 평가 척도에 대해 각 척도들 간의 함수적 관계를 단순히 정의된 식으로부 터 도출하기는 어렵다. 따라서 Johnson (1990)이 제시한 진단 척도들 간의 관계를 보다 이해하기 쉽도 록 그래프에 의한 방법을 적용하여 관계를 규명하였으며, 본 연구에서는 기존의 연구에서 각각의 진단 측도들 간의 관계를 방사형 차트를 활용하여 보다 쉽게 규명하는 방법을 제안하였다.

\section{2. 진단 검사 평가측도에 대한 방사형 그래프의 표현}

Table 1.1의 결과로 부터 Johnson (1999)는 $2 \times 2$ 빈도표의 값을 $2 \times 2$ 그래프인 2 차원 평면상의 축(coordinate axes)과 4각형 상자(subject box)를 이용하여 민감도와 예측도 등을 표현하였다. 다 음의 Figure 2.1 로부터 민감도는 $y$ 축의 $\mathrm{TP}+\mathrm{FN}$ 의 길이로 $\mathrm{TP}$ 의 길이를 나눈값 $(\mathrm{TP} /(\mathrm{TP}+\mathrm{FN}))$ 이 며, 특이도는 $\mathrm{FP}+\mathrm{TN}$ 의 길이로 $\mathrm{TN}$ 의 길이를 나눈 값 $(\mathrm{TN} /(\mathrm{FP}+\mathrm{TN}))$ 으로 표현된다. 또한 양성 예측값(점진결과가 양성일 때, 환자가 질병이 있는 경우)은 $\mathrm{TP}+\mathrm{FN}$ 의 길이로 $\mathrm{FP}$ 의 길이를 나눈 값 $(\mathrm{FP} /(\mathrm{TP}+\mathrm{FN}))$ 이며, 음성예측값(검진결과가 음성일 때, 환자가 질병이 없는 경우)은 $\mathrm{FN}+\mathrm{TN}$ 의 길 이로 $\mathrm{FN}$ 의 길이를 나눈값 $(\mathrm{FN} /(\mathrm{FN}+\mathrm{TN}))$ 이다.

이와 같이 Johnson (1999)가 제시한 그래프는 범용 프로그램으로 구현하기 어렵고, 그래프에 표현된 각 측도들 간의 관계를 이해하는데 한계가 있다. 


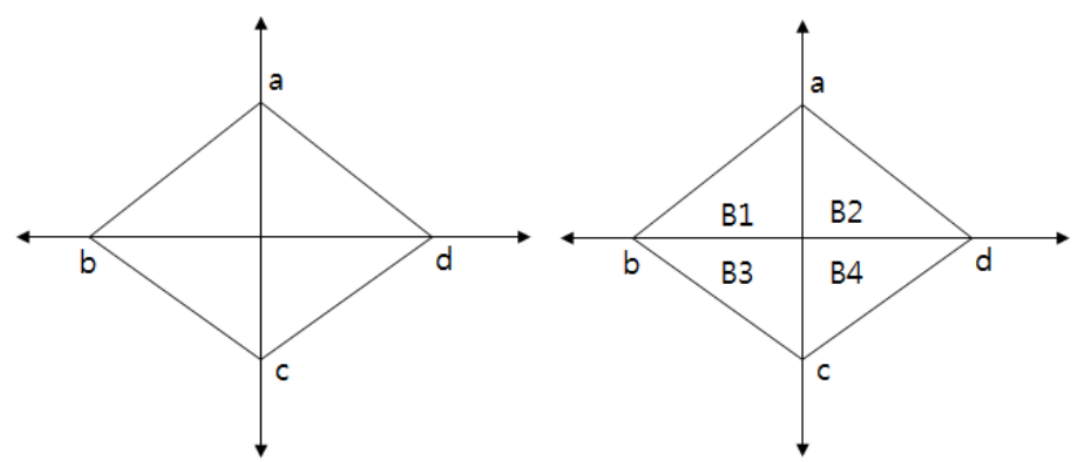

Figure 2.2. Radar diagram for result of diagnostic test

본 절에서는 Johnson (1999)의 방법을 개선하여 방사형 그래프를 이용한 진단 측도들 간의 관계를 규명 하고자 한다. Figure 2.2에 주어진 방사형 그림은 원점을 중심으로 4 개의 직각 삼각형으로 구성되어 있 다. 각 면적은 $B_{1}=a b / 2, B_{2}=a d / 2, B_{3}=b c / 2$ 그리고 $B_{4}=c d / 2$ 이다. 진단 검사 방법을 평가하는 측도들의 정의를 방사형 그림을 구성하는 직각삼각형의 면적 $B_{1}, B_{2}, B_{3}$ 그리고 $B_{4}$ 을 사용하여 나타내 면 다음과 같다.

a) 민감도 : $\mathrm{Se}=\frac{a}{a+c}=\frac{B_{1}}{B_{1}+B_{3}}=\frac{B_{2}}{B_{2}+B_{4}}$

b) 특이도 : $\mathrm{Sp}=\frac{d}{b+d}=\frac{B_{2}}{B_{1}+B_{2}}=\frac{B_{4}}{\left(B_{3}+B_{4}\right)}$

c) 의양성 비율 : $\mathrm{FPR}=1-\mathrm{Sp}=\frac{b}{b+d}=\frac{B_{1}}{B_{1}+B_{2}}=\frac{B_{3}}{B_{3}+B_{4}}$

d) 의음성 비율 : $\mathrm{FNR}=1-\mathrm{Se}=\frac{c}{a+c}=\frac{B_{3}}{B_{1}+B_{3}}=\frac{B_{4}}{B_{2}+B_{4}}$

e) 양성우도비 : $\mathrm{PLR}=\frac{\mathrm{Se}}{1-\mathrm{Sp}}=\frac{\mathrm{Se}}{\mathrm{FPR}}=\frac{a /(a+c)}{b /(b+d)}=\frac{a(b+d)}{b(a+c)}=\frac{B_{1}+B_{2}}{B_{1}+B_{3}}$

f) 음성우도비 : $\mathrm{NLR}=\frac{1-\mathrm{Se}}{\mathrm{Sp}}=\frac{\mathrm{FNR}}{\mathrm{Sp}}=\frac{c /(a+c)}{d /(b+d)}=\frac{c(b+d)}{d(a+c)}=\frac{B_{3}+B_{4}}{B_{2}+B_{4}}$

성질 1) 민감도와 특이도 간의 관계

진단 검사를 평가하는 여러 측도들의 성질들을 Figure 2.2 에 주어진 방사선 그림의 삼각형 면적 $B_{1}$, $B_{2}, B_{3}$ 그리고 $B_{4}$ 를 사용하여 나타내면 다음과 같다.

$$
\mathrm{Se}-\mathrm{Sp}=\frac{B_{2}\left(B_{1}-B_{4}\right)}{\left(B_{2}+B_{4}\right)\left(B_{1}+B_{2}\right)} .
$$

이와 같은 관계로부터 방사형 그래프의 면적을 이용하면 다음의 성질을 만족한다.

1) $B_{1}=B_{4}=B_{2}$ 이면 $\mathrm{Se}=\mathrm{Sp}=0.5$

2) $B_{1}=B_{4} \neq B_{2}$ 이면 $\mathrm{Se}=\mathrm{Sp} \neq 0.5$

3) $B_{4}<B_{1}<B_{2}$ 이면 $0.5<\mathrm{Sp}<\mathrm{Se}$

4) $B_{4}<B_{2}<B_{1}$ 이면 $\mathrm{Sp}<0.5<\mathrm{Se}$ 
Table 3.1. Test result of Coronary-artery disease

\begin{tabular}{ccccc}
\hline & & \multicolumn{2}{c}{ Coronary-artery disease } & Total \\
\cline { 3 - 4 } & & Present & Absent & 345 \\
Clinical & Positive & 300 & 45 & 655 \\
Test & Negative & 200 & 455 & 1000 \\
\hline
\end{tabular}

5) $B_{2}<B_{4}<B_{1}$ 이면 $\mathrm{Sp}<\mathrm{Se}<0.5$

6) $B_{2}<B_{1}<B_{4}$ 이면 $\mathrm{Se}<\mathrm{Sp}<0.5$

7) $B_{1}<B_{2}<B_{4}$ 이면 $\mathrm{Se}<0.5<\mathrm{Sp}$

8) $B_{1}<B_{4}<B_{2}$ 이면 $0.5<\mathrm{Se}<\mathrm{Sp}$

성질 2) 의양성 비율은 방사형 그래프의 면적들로부터 다음과 같은 성질을 만족한다.

1) $B_{1}=B_{2}$ 또는 $B_{3}=B_{4}$ 이면 $\mathrm{FPR}=0.5$

2) $B_{1}<B_{2}$ 또는 $B_{3}<B_{4}$ 이면 $\mathrm{FPR}<0.5$

3) $B_{1}>B_{2}$ 또는 $B_{3}>B_{4}$ 이면 $\mathrm{FPR}>0.5$

성질 3) 의음성 비율 성질은 방사형 그래프의 면적으로부터 다음과 같은 성질을 만족한다.

1) $B_{1}=B_{3}$ 또는 $B_{2}=B_{4}$ 이면 $\mathrm{FNR}=0.5$

2) $B_{1}>B_{3}$ 또는 $B_{2}>B_{4}$ 이면 $\mathrm{FNR}<0.5$

3) $B_{1}<B_{3}$ 또는 $B_{2}<B_{4}$ 이면 FNR $>0.5$

성질 4) 양성우도비와 음성우도비 간의 관계는 방사형 그래프의 면적으로부터 다음을 만족한다.

1) $B_{2}=B_{3}$ 이면 $\mathrm{PLR}=\mathrm{NLR}=1$

2) $B_{2}>B_{3}$ 이면 PLR $>1$ 그리고 NLR $<1$

3) $B_{2}<B_{3}$ 이면 $\mathrm{PLR}<1$ 그리고 NLR $>1$

\section{3. 응용예제}

Sackett 등 (1991, p.95)에 제시된 관상동맥 질병에 대한 진단 검사 자료를 이용하여 Table 3.1에 대한 진단 검사 방법에 대한 진단 평가 측도값들을 구하면 자료로부터 민감도가 0.6 이라는 의미는 진단 검사 를 받은 1000 명 중에서 500 명이 관상동맥 질환이 있는 것으로 나타났고, 이들 중 300 명이 질환이 있는 사람으로 판별하고 있음을 나타내며, 특이도는 질환이 없는 500 명 중에서 진단 검사 결과 음성으로 나타 난 455 명을 나타낸다. 의양성 비율은 “ 1 - 특이도"로서 0.09 로 나타났고, 의음성 비율은 " 1 - 민감도" 로서 0.4 로 분석되었다. 또한 양성 우도비는 의양성 비율과 민감도의 비로 나타나며, $0.6 / 0.09=6.67$ 이 며, 음성 우도비는 “의음성비율과 특이도간의 비”로 나타나며, $0.4 / 0.91=0.44$ 로 구해진다. 이를 정리 하면 다음과 같다.

a) 민감도 : $\mathrm{Se}=0.6$ 


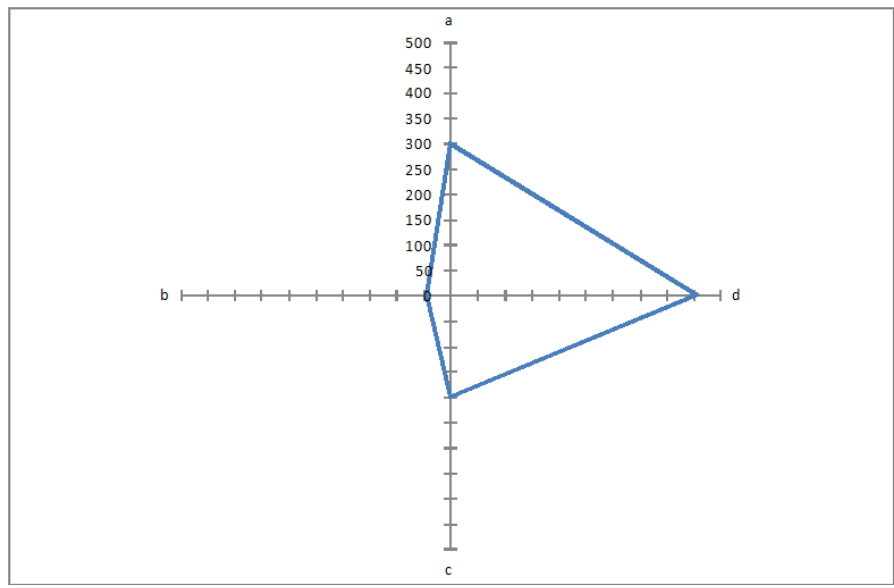

Figure 3.1. Radar diagram from Table 3.1

b) 특이도 : $\mathrm{Sp}=0.91$

c) 의양성 비율 : $\mathrm{FPR}=0.09$

d) 의음성 비율 : $\mathrm{FNR}=0.4$

e) 양성우도비 : PLR $=6.67$

f) 음성우도비 : NLR $=0.44$

주어진 Table 3.1의 자료에 대한 Microsoft Excel을 사용하여 방사선 그래프로 표현하면 다음의 Figure 3.1 과 같다.

Figure 3.1로부터 Figure 2.2에서 정의한 삼각형의 면적의 크기가 $B_{3}<B_{1}<B_{4}<B_{2}$ 를 만족한다. 따라서 앞에서 정의한 성질들을 이용하면 $B_{1}<B_{4}<B_{2}$ 이므로 $0.5<\mathrm{Se}<\mathrm{Sp}$ 이다. 즉, 측도간의 관계 로부터 특이도가 민감도 보다 상대적으로 높으며, 따라서 관상동맥 질환이 없는 사람을 음성으로 판정할 확률이 높음을 의미하기 때문에 진단 방법은 적절함을 나타낸다.

또한 $B_{3}<B_{4}, B_{3}<B_{1}$ 이므로 $\mathrm{FPR}<0.5$ 와 $\mathrm{FNR}<0.5$ 을 각각 만족하기 때문에, 의양성판정과 의음성비율은 0.5 보다 작게 되어 진단방법이 타당함을 나타낸다. 그리고 $B_{3}<B_{2}$ 이므로 PLR > 1 와 $\mathrm{NLR}<1$ 을 만족하여 양성우도비는 1 보다 크고 음선우도비는 1 보다 작아 관상동맥 질환이 있는 사람들 을 적절히 판정할 수 있는 진단 방법으로 판단할 수 있다.

\section{4. 결론}

진단 검사를 평가하는 측도의 선택에 대한 여러 의견이 있지만 본 논문에서는 측도의 선택에 대한 논의 보다는 측도의 특징이나 관계를 함수 형태보다는 방사형 그림을 사용함으로서 Jonhoson의 방법에 비 해 좀 더 쉽게 이해할 수 있음을 보였다. $2 \times 2$ 빈도표에 대한 방사형 그림은 범용 프로그램인 Microsoft Excel을 사용하여 쉽게 구현할 수 있다. 특히 서로 다른 진단 측도들 간의 관계를 방사형 그래프의 면적 을 이용하여 표현함으로서 비록 방사형 그림을 통해서 진단 검사를 평가하는 측도들의 정확한 값들을 알 수 있는 것은 아니지만, 방사형 그래프의 각 영역의 면적과 측도들 간의 관계를 이용하여 보다 용이하게 이들 간의 관계를 이해할 수 있다는 장점이 있다. 


\section{References}

Bradly, G. W. (1993). Disease, Diagonstic, and Decisions, New York, Wiley.

Johnson, K. M. (1999). The two by two diagram: A graphical truth table, Journal of Clinical Epidemiology, 52, 1073-1082.

Kraemer, H. C. (2004). Reconsidering the odds ratio as measure of $2 \times 2$ association in a population, Statistics in Medicine, 23, 257-270.

Linn, S. (2005). New patient-oriented diagnostic test characteristics analogous to the likelihood ratios conveyed information on trustworthiness, Journal of Clinical Epidemiology, 58, 450-457.

Michael, P. (2007). Excel 2007 in Easy Steps, In Easy Steps Limited.

Ransohoff, D. F. (2002). Challenges and oppertunities in evaluating diagnostic tests, Journal of Clinical Epidemiology, 55, 1178-1182.

Sackett, D. L., Haynes, R. B., Guyatt, G. H. and Tugwell, P. (1991). Clinical Epidemiology, 2nd ed. Boston, MA: Little Brown.

Walter, S. D. (2000). Choice of effect measure for epidemiological data, Journal of Clinical Epidemiology, 53, 931-939. 


\title{
진단검사에서 측도들의 효과적인 표현: 그래프를 활용한 방법
}

\author{
조태경 ${ }^{a, 1} \cdot$ 손창균 $^{a}$ \\ ${ }^{a}$ 동국대학교 정보통계학과
}

(2012년 10월 15일 접수, 2012년 11월 12일 수정, 2012년 11월 27일 채택)

요 약

임상연구나 역학조사에서 $2 \times 2$ 분할표는 요약통계를 표현하는데 매우 유용하게 활용된다. 이때 $2 \times 2$ 분할표의 4 개 셀값들은 위험비, 상대위험비, 또는 승산비 등과 같은 척도를 계산하는데 이용된다. 본 논문에서는 민감도, 특이도, 예측도, 우도비와 같은 진단 측도들 간의 관계를 쉽게 이해할 수 있도록 MS-office 액셀을 이용한 방사형 그래프를 통해 시각화하는 개선된 방법을 제안하였다. 몇 가지 수치적 예제를 활용하여 제안된 방법의 활용성을 제시하였다.

주요용어: 진단검사, 민감도, 특이도, 예측도, 우도비.

1교신저자: (780-714) 경북 경주시 석장동 707 번지, 동국대학교 정보통계학과, 교수.

E-mail: tkcho@dongguk.ac.kr 